\title{
Designing Speculative Civics
}

\author{
Carl DiSalvo ${ }^{1}$, Tom Jenkins ${ }^{1}$ and Thomas Lodato ${ }^{2}$ \\ ${ }^{1}$ Digital Media Program \\ School of Literature, Media, and Communication \\ Georgia Institute of Technology \\ Atlanta, GA, USA \\ ${ }^{2}$ Center for Urban Innovation \\ School of Public Policy \\ Georgia Institute of Technology \\ Atlanta, GA, USA \\ cdisalvo, tom.jenkins, thomas.lodato@gatech.edu
}

\begin{abstract}
As human computer interaction design research continues to expand domains, civics is emerging as an important subject through which to explore how computation shapes our public lives. In this paper we present and reflect upon a series of research through design (RtD) projects that investigate speculative civic contexts. From this, we identify and discuss tactics that can be employed in RtD projects: RtD as Representations of Systems Yet-to-Come, RtD as Prototyping Systems and RtD as Use of a System. Then we identify and discuss thematic interpretations of civics that emerged through our designs: Mediated Civics, Computed Civics, and Proxied Civics. This work contributes to discourses of speculative design, research through design, and those of civics in human computer interaction design research.
\end{abstract}

\section{Author Keywords}

Civics; Public Design; Research Through Design, Speculative Design, Speculative Civics

\section{ACM Classification Keywords}

H.5.m. Information interfaces and presentation (e.g., HCI): Miscellaneous.

\section{INTRODUCTION}

With computation pervading most all aspects of life, civics have become yet another site to understand, explore, and refine human computer interaction design. Over the past decades, computational technologies have altered the character of contemporary public life. Personal computers, smartphones, sensor grids, networked CCTV, online portals, network sentiment analysis are inserted into the civic domain and packaged as new umbrella terms: the Internet of Things (IoT), Smart Cities, Civic Hacking, and e-Government, to name a few. While these terms are as

Permission to make digital or hard copies of all or part of this work for personal or classroom use is granted without fee provided that copies are not made or distributed for profit or commercial advantage and that copies bear this notice and the full citation on the first page. Copyrights for components of this work owned by others than the author(s) must be honored. Abstracting with credit is permitted. To copy otherwise, or republish, to post on servers or to redistribute to lists, requires prior specific permission and/or a fee. Request permissions from Permissions@acm.org.

CHI'16, May 07 - 12, 2016, San Jose, CA, USA

Copyright is held by the owner/author(s). Publication rights licensed to ACM.

ACM 978-1-4503-3362-7/16/05 ..\$15.00

DOI: http://dx.doi.org/10.1145/2858036.2858505 much branding and marketing as they are actual new directions and emerging practices, both academics and practitioners (e.g. White House Smart Cities Initiative and Bloomberg Philanthropies) are directing resources to these efforts to understand the role of contemporary computational technologies in public life.

In the context of this paper, we are concerned with the emerging relationship between computation and civics. By civics, we mean the modes through which individuals take on the role of citizen, involving processes of governance and politics. While traditional civics is at times limited to the power structure of the nation-state (polity), we use the term more loosely. For this paper, civics includes the "institutional void" [32] that refigures classical-modernist notions of control, power, and rights into more fluid, discursive networks. We understand civics as containing the structures, practices, and experiences of public life. This includes notions of the state and government, ranging from election mechanisms like voting to the role of the state in social service provisioning to issues of legitimacy, participation, and citizenship. It also extends beyond formal state and government contexts to include civil society, activism, advocacy, and citizen-led initiatives meant to interface with the state or government and shape public life, including various modes of protest, direct action, and organizing. In between these two points, civics also includes activities of so-called "extrastatecraft" [21], and DIY infrastructure [35] that blends the activities and responsibilities of the state with independent or amateur efforts, resulting in novel, hybrid endeavors such as efforts to design and deploy alternative power grids, community mesh networks, and alternative sewer systems. The overlap and intersection of civics and computation is part of a larger discourse of public design, which considers (amongst other things) the role of computation in contemporary matters-ofconcern $[16,18]$. In the case of civics, these concerns relate to the nature of governance, politics, and government in a post-digital age.

In this paper the relationship between computation and civics is explored through design. Specifically, we present three design projects, each of which explores and expresses a different configuration and experience of civics. Through this work, we articulate both tactics of research through design and themes on civics. We characterize this work as 

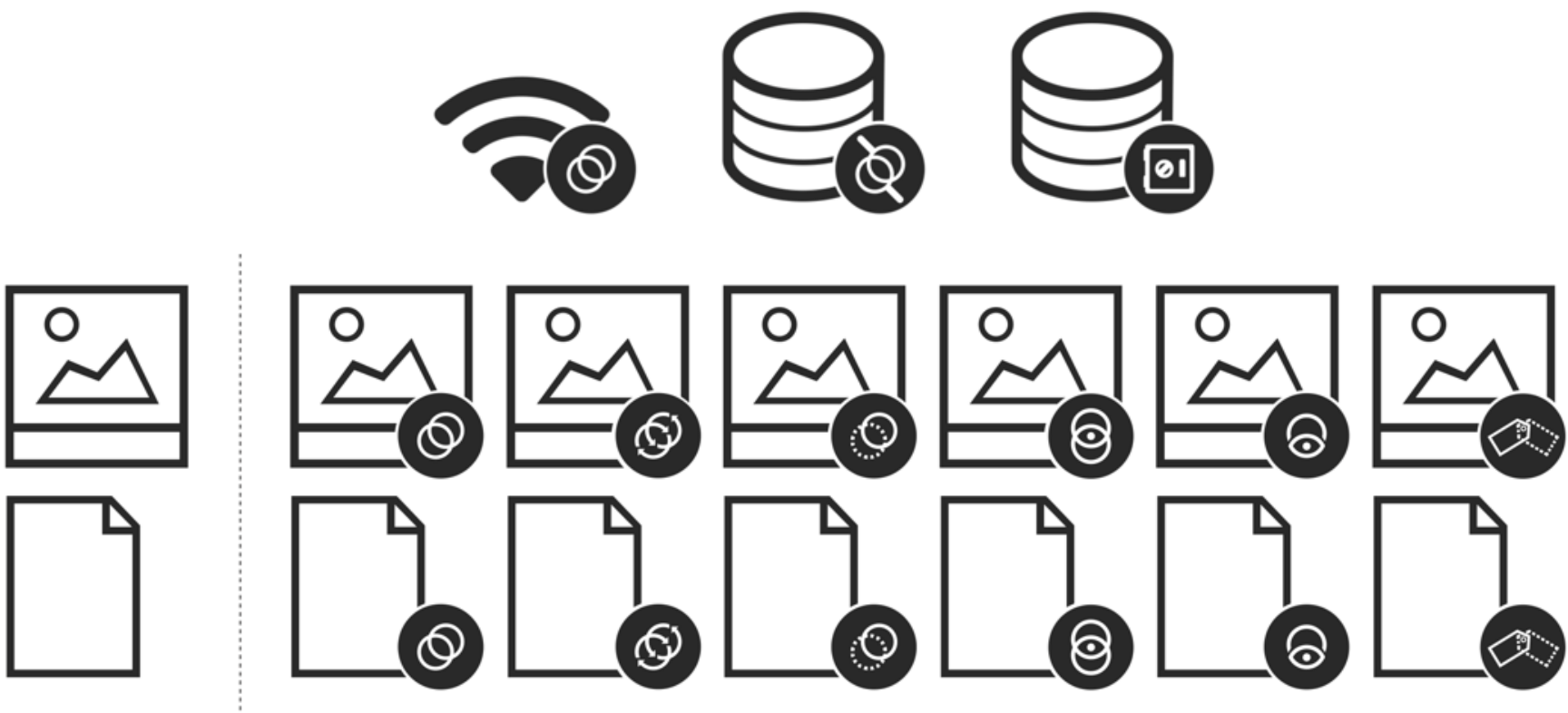

Figure 1: Icons representing various process and file states from The Division of Domestic Data: top (left to right), secured WiFi, server for file disclosure and discovery, and escrow server; bottom (left to right), jointly owned, jointly synced, secure transfer, jointly viewable and monitored, locked from view and monitored, and mandatory untagging

a kind of speculative civics: a way to explore potential, alternative, and future conditions by articulating their existence in generative forms, with a particular focus on the complications of governance and politics disposed by computational technologies.

\section{SPECULATING ON CIVICS}

Similar to many contemporary research through design projects, in our work we are attempting to use to design to materialize and explore possible configurations of technology and public life. While some design theorists argue that design is almost always speculative, in that it is almost always about the future $[37,46]$, this is not the case with civics, particularly with regards to design and technology. We are using the phrase "speculative civics" to signal that our approach to civic technology is grounded in an informed imaginative projection of what our experience of civics might be.

Most "civic tech" is primarily concerned with the immediate or near term use of information and communications technologies to streamline the activities of governance, advocacy, direct action, and social service provisioning. In contrast to "civic tech," our research envisions future civic conditions and then designs around these conditions. We are not the first to speculate on civics. There is indeed a rich history of imagining the future of government and life in the public sphere. Moreover, it is common to collapse notions of "the city" or urbanism, with notions of civics. So, many "cities of tomorrow" projects include - to varying degrees-explorations of notions of governance or social service provisioning. These design projects can be seen as a continuation of that practice.

In using the phrase speculative civics, we are also aligning ourselves with practices of speculative design. Speculative design has a history that stretches, at least, back to the mid$20^{\text {th }}$ Century with the work of design groups such as Archigram and SuperStudio [11,44]. Over the past decade, speculative practices in design have been reinvigorated through work falling under a range of labels, including critical design [19,20] and design fiction [5]. Within the field of Human-Computer Interaction research and design, there are multiple points of affinity with the broader field of speculative design, mostly made through intersection with and interrogations of critical design [2,25] and design fiction [34,45] . Furthermore, within both HCI and design there is debate about these practices and whether, and to what extent, these practices are in fact novel or innovative $[42,46]$.

Our approach to speculation is to treat it as a tactic of research through design $(\mathrm{RtD})[7,24,27,28]$. In what follows we present three projects, each of which began with a speculation about civics that directed design activities. From these design activities we drew insights into both tactics of RtD and civics. Because the activities of designing were foundational to the research, we describe them within each project description, rather than segregating them into a separate methods section. 


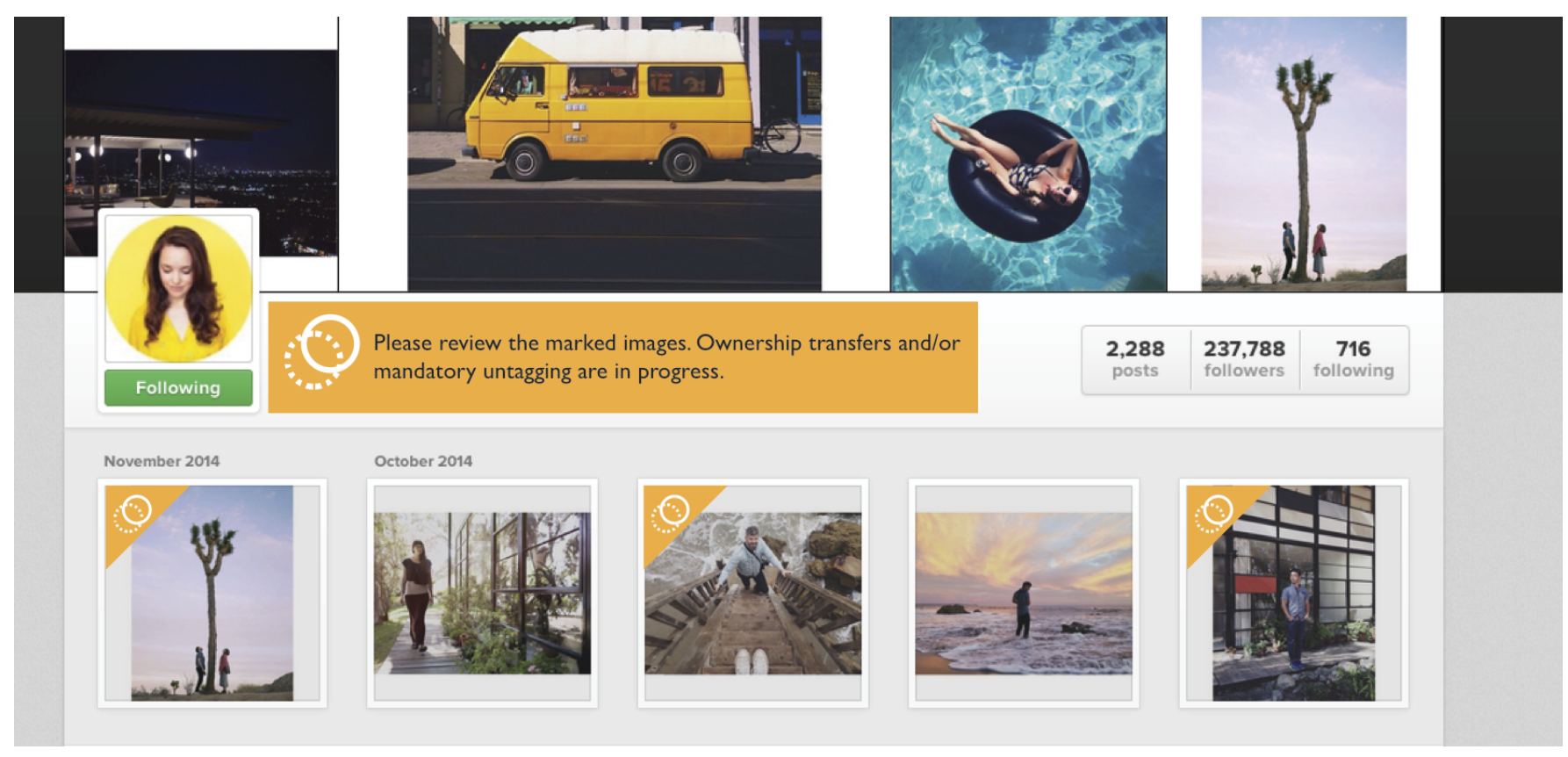

Figure 2: Icons from The Division of Domestic Data on an Instagram feed

\section{THE DIVISION OF DOMESTIC DATA}

The Division of Domestic Data is a design project that consists of an icon set, series of sketches, and an informational pamphlet. The project explores the potential legal (rather than sentimental) standing of digital artifacts in the context of divorce. Focusing on the particular statues of divorce within Fulton County (Atlanta, GA USA), this project relates to the various potential legal states of digital files, folders, and images during legal separation, as well as provisions related to dividing shared profiles and services (e.g. WiFi and data plans). The Division of Domestic Data reflects on contemporary ideas of mutual ownership, the weirdness of digital possessions, and emerging expectations of post-digital property holding.

The Division of Domestic Data followed a sketchbook approach to RtD. During the initial phase of researching the design space, we reflected on the particular statutes and regulations about separation and divorce through sketches. These sketches responded to the current conditions, and provided early themes of what issues were most salient. At this phase, issues related to digital files and possessions emerged.

After a second phase of sketching and critique, we further refined the topic area to focus on ways that digital files might be labeled as they are divided during separation and divorce. This graphic design approach was selected instead of other possible approaches to the subject matter, such as service or interaction design - as well as from among other issues that might be relevant, like automating or streamlining divorce. Once selected, icons to represent this process of separation were developed through iterative refinement paired with studio critiques. The Division of Domestic Data was developed over seven weeks.
The Division of Domestic Data project is grounded in the real-world divorce practices in Fulton County, GA. In Fulton County, the act of filing for separation/divorce activates the County's Automatic Domestic Standing Order (ADSO). The ADSO protects the two parties and any dependents from malicious, emotional, or premature action by either party prior to an official hearing and settlement. Amongst the twelve sections of the ADSO, the design project focuses on two important themes: (1) protection from the unlawful withholding, destruction, or sale of shared property, and (2) protection against undue burden due to premature division of responsibilities/services. An example of (2) might be one party cancelling car insurance, thereby legally obligating the other to purchase a new policy.

Conspicuously missing from the ADSO and its understanding of property is any mention of digital things. While property and services cannot be destroyed, sold, cancelled, or withheld, the ADSO only means physical property and services, thus failing to account for the myriad digital things that compose out lives. For example, a hard drive is protected by the ADSO insofar as the hard drive is a physical possession, while its contents are not protected. The Division of Domestic Data explores how digital possessions and services might be included in the provisions of the ADSO.

\section{Initial Design Work}

The project engaged in reflective research-through-design methodology [24]. The project began by outlining the current stipulations found in the ADSO, and outlining (1) unprotected shared/joint digital possessions (e.g. music files, digital photos, and shared folders) and (2) unprotected services (e.g. wireless access, remote server space, and 
cellular plans). With these two categories in mind, a comprehensive collection of existing icons and digital states was assembled. For example, remotely stored files often have three states-un-synchronized, synchronizing, and synchronized - which can also be mapped onto a remote storage service-indexing, syncing, paused sync, and synced. Alongside these icons, a collection of icons representing existing relational/relationship statuses was assembled. These collections served as a base from which to create new icons and consider new file and service states.

\section{Icon Making as Speculating}

Icons were developed around two categories. One group of icons was created to mark the current state of various digital things - files, folders, services, and collections - that related to the processes of separation/divorce-disclosure of assets, secure storage of assets (e.g. escrow), and transference of held property. These icons focus on the ways digital property might slot into existing processes of separation/divorce, such as marking files as under review or as locked from deletion. This collection of icons included ways of representing the important role of ICTs in everyday life. For example, one icon marks a WiFi network to which no party can change the password-thereby protecting parties from undue burden (See Figure 1 (top) for an example of these icons). A second group of icons was created to account for new states of digital things: jointly owned and jointly synced files, mutually deleted and mutually locked files, and files that maintain their ownership/version records (See Figure 1 (bottom) for an example of these icons).

During this process, we created intermediate collections of icons, which were used in sketches, scenarios, and user flows (See Figure 2 for an example). Situating these icons allowed for reflection on missing states, confused meanings, and over-articulation of the nature of digital property rights. For example, the icon for mutual deletion (two dashed interlocking rings, not shown) was developed in response to the icon for secure transfer (one solid ring interlocked with a dashed ring), or one party owning a file while the other party deleting any copies. Similarly, the notion of mutually locked possessions (e.g. tax returns with private information neither party wants to get rid of nor wants the other to see) was developed after receiving feedback about digitally managing mutually assurance against breaches of security.

\section{Conclusion}

The Division of Domestic Data builds on work already existing within the HCI and interaction design community. Divorce, like other significant life events, does not mesh well with the models of users inscribed into computational systems. From issues of categorical finality exposed by gender reassignment [31] to problems of individuated access exposed by the stewardship of deceased users on social networks $[8,9]$ to assumptions favoring longevity and persistence rather than legacy and ephemerality [38-41],
HCI and interaction design frequently have a bias toward more normative user models. The circumstances of divorce highlights how computational systems favor (and even profit from) increasing/increased connectivity, while failing to account for the ways a user might also be a composite of two or more people (i.e. a shared Netflix movie queue)something that is thrown into stark relief during disentanglement. While privacy has been a grave concern with regards to computational systems, constructions of privacy assume that there exists a de facto formal (and so formaliable) relationship amongst parties. If any broad lesson can be culled from the many scholars working within this general area, we argue that computational systems are woefully biased toward positive, celebratory, and normative life events, negating the significant place of crises, trauma, and difficulty in everyday life. This bias both alienates users of computational systems and implicitly rejects the values of third-wave HCI and user experience design.

\section{DATA DEMOCRACY}

Data Democracy is a design project that engaged the emerging rhetoric of smart cities, and digital democracy, and playfully probed the utility of common techniques used in these contexts. Beginning with a survey of available civic and e-government technologies, we identified thematic similarities within these technologies, such as mitigating bureaucracy, increasing access, and real-time monitoring, as well as institutional mechanisms, such as the emergence of third-party civic service intermediaries. These themes gave us directions to critically reflect on a potential end goal of civic technology, namely passive tracking of real-time sentiment.

After generating different proposals for how civic tech might embrace this idea - such as using social media outlets as voting portals - we chose to examine how third-party civic service intermediaries might offer a business-tobusiness solution for government officials to understand public sentiment around issues in a city. Using open-source web technologies, the we built a prototype that investigates these assumptions.

The goal of Data Democracy was to follow a neoliberal logic of applying contemporary marketing technologies to the context of civics, and particularly governance. Instead of helping produce better customer service, this technology gauged public sentiment around issues. Understanding realtime, geo-located feelings about everything from parking to potholes to permitting would be useful at all levels of civic planning. Indeed, this has been the concept driving many civic applications and projects from organizations like Code for America. The most celebrated civic technologies resemble systems like crowd-sourced pothole reporting tools (http://seeclickfix.com) or fire hydrant adoption applications (http://adoptahydrant.org), where residents claim proprietorship of a fire hydrant and dig it out after a large snowfall. 


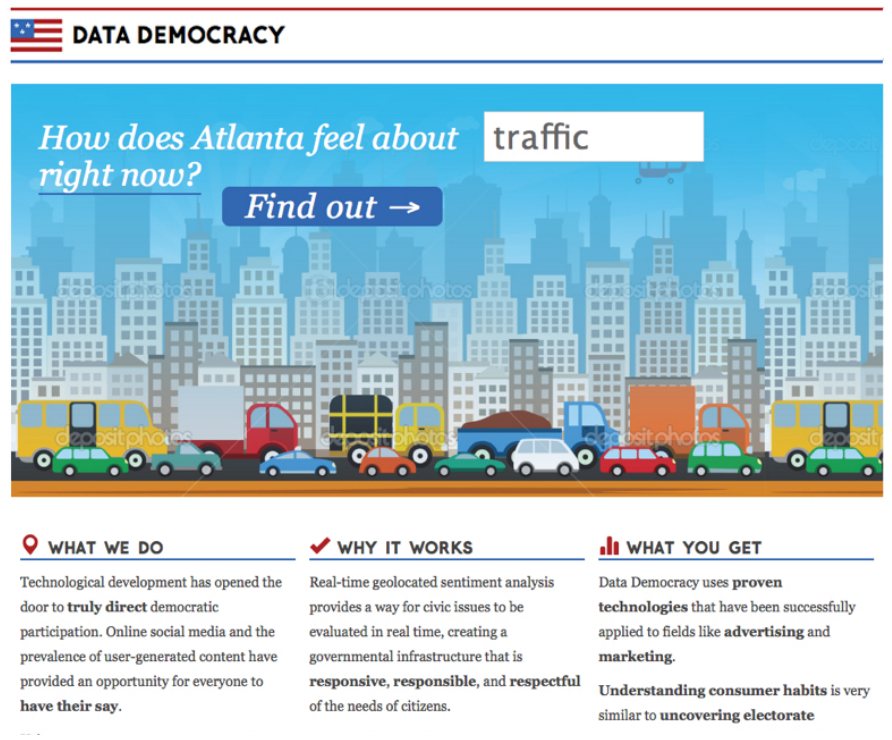

Figure 3: Data Democracy's home screen (left) and analysis screen (right).

Data Democracy pushes at this trend. At one level, this project asks "Instead of a two- or four-year election cycle, might it be possible to operate and govern democratically from constant data-collection?" Of course, at another level this premise reveals a paradox: a government that siphons passive data as representational political expression and action is an odd sort of democracy. In that light, Data Democracy is meant playfully probe technocratic, datadriven efforts in the public sphere and use "big data" to make government more reactive and responsive, despite the inevitable cost to truly representative pluralism [13].

Data Democracy, then, is an example of emerging technical practice applied to present conditions. It is an application of a technology that illustrates the "appification" of cities and urban services $[12,48]$. It takes as a given assumptions that civic capabilities and resource provisioning techniques are and should be discrete and modular. It attempts to procedurally enact some of these assumptions by first representing them as computation and then pushing them to extremes. It does this to understand and reveal some of the motivations that operate behind the scenes of technologies like these, as well as to illustrate how this line of thinking might result in producing fundamentally undemocratic technologies in the future [43].

\section{Scripting as Speculating}

The project itself is a web application with two major parts: a prompt and a visualization. The first displays a large text input to a user, offering them the prompt "What does Atlanta think about right now?" alongside a button that reads "Find out $\rightarrow$ " (See Figure 3, left). After the user enters a phrase, such as "traffic," and pushes the button, the application searches twitter for tweets within 5 miles of local coordinates that contain the word "traffic." These tweets are then analyzed for two attributes. First, the tweet's geolocation is stored in an array. Next, the content of these tweets are analyzed using a text-to-sentiment API provided by datasciencetoolkit.org.

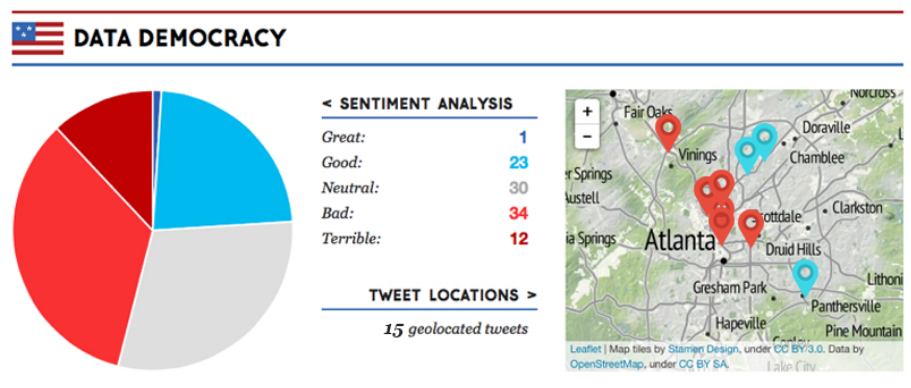

\section{Atlanta thinks that traffic is bad!}

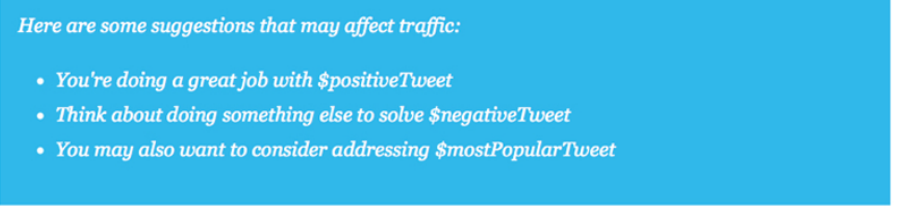

" SHOW RECENT 'TRAFFIC' TWEetS NEAR 33.787423, -84.372597
The second screen visualizes of all of this scraped and interpreted information (See Figure 3, right). Every analyzed tweet is placed onto a map and given a colorcoded marker according to the sentiment analysis. These sentiments are also used to create a pie chart of how the senders of the tweets feel about the issue at hand. Tweets were categorized as being Great, Good, Neutral, Bad, and Terrible. Together, these were taken as how Atlanta "felt" about the search terms, and where certain sentiments were strongest. Conceivably, this output would be used to gauge feeling around issues in the city, providing grist for technocratic governance.

Obviously, this is a simplistic approach. The scripts that generated the page rely on geolocated tweets, leaving others that may be from Atlanta but not geolocated underrepresented. Further, many of the issues that might be searched for in Atlanta had other definitions that would dilute the results. For example, traffic is a huge problem in a city that has - on average - a 40-minute commute. Tweets that contain the word "traffic" would be predominantly negative during morning and afternoon rush hours. But this result includes tweets that are not simply about automobile traffic or commuting. On Twitter, searches for traffic, even specifying geolocated tweets only, will result in many accounts tweeting and retweeting advertisements that promise to increase web traffic. Finally, Data Democracy has nothing to offer those who choose not to use Twitter. By excluding people like these from the civic dialogue, Data Democracy redefines participation in a democratic system to exclusively mean "choosing to use certain kinds of social media."

\section{Conclusion}

While the initial intention of the design was to critically explore perspectives on smart cities and digital democracy that purport to streamline representational politics through data collection, the resulting system did not so much produce critique as it simply exemplified the fragility and 

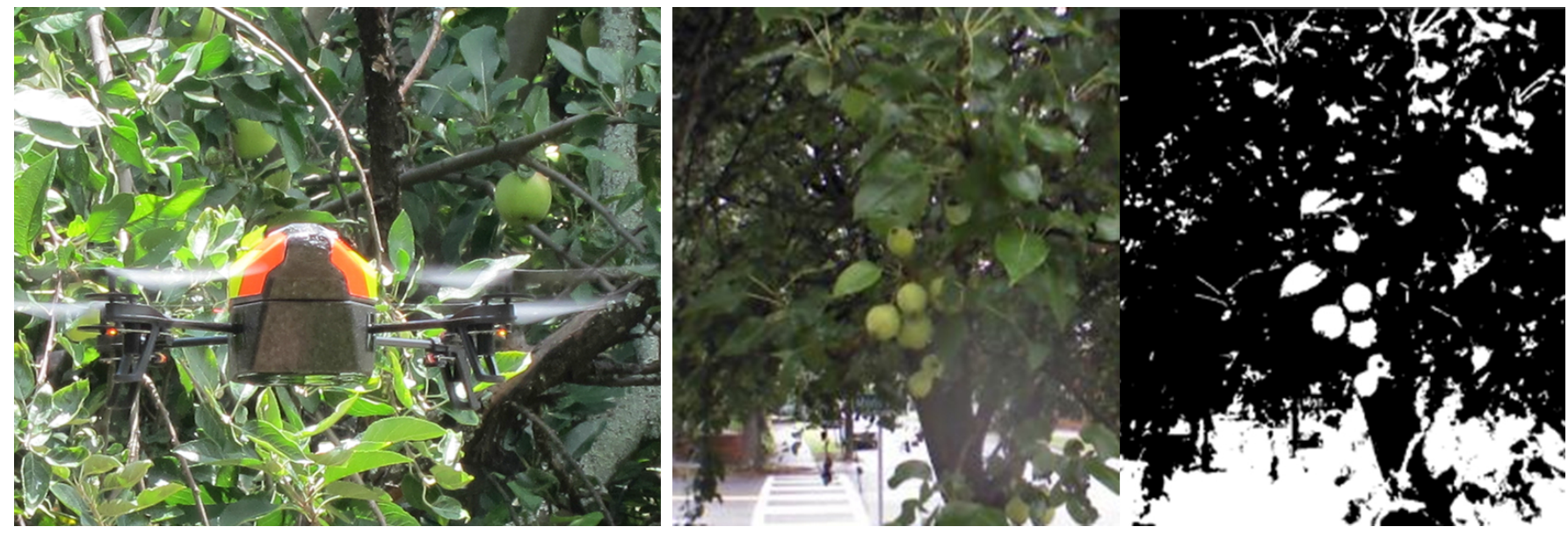

Figure 4: Drone flying near a pear tree (left), and drone footage of pear tree unprocessed and processed.

awkwardness of such approaches. The system worked just well enough to seem interesting, and possibly even useful. Taken as a way of getting insight into some small sample of people participating in a particular technological platform, why not consider sentiment in aggregate?

The challenge in such work is that using a technical implementation to produce criticism of technical practices in the same mode seems to up speculating on the method of implementation, rather than on the condition underlying it. Moreover, using a publicly-available API black-boxed some of the assumptions that should be made visible. The issues that arise, then, are not understood as critical questions about how civics is being is re-constituted through such techniques, but rather pragmatic questions abut how to make the technology work "better."

\section{DRONES FOR FORAGING}

Foraging is the collection of naturally growing foodstuffs from places other than farms or orchards. Examples of foraging include collecting pears from trees in public parks, fennel along train tracks, or blueberries from bushes in residential yards. Foragers makes use of this accidental abundance, collecting, selling, sharing, consuming, these, essentially free, foodstuffs.

One of the challenges of foraging is keeping track of the ripeness of fruit, in order to know when to schedule a pick. Unlike an orchard where the trees are co-located, the fruit trees that are picked by urban foragers are distributed across the city. The amount of time and labor required to keep track of the status of the fruit on these trees is substantial, particularly for a volunteer organization. Monitoring the fruit is important: wait to long to schedule a pick and the fruit will fall to the ground and spoil, schedule a pick to early, and the fruit will not be ready-in either case the time and labor of the volunteers will be wasted.

Since 2013, we have been collaborating with Concrete Jungle, a foraging collective in Atlanta. Concrete Jungle is a volunteer organization with core of 4-6 members and a volunteer base of upwards of 100 people. One of the distinctive aspects of Concrete Jungle is that they donate the fruit they collect to local social service providers, such as food pantries, women's shelters, and churches that provide meal services. In this way the work of Concrete Jungle can be considered a kind of civics: a provisioning for public good.

The Drones for Foraging project is a research through design project that explores the use of unmanned aerial vehicles (UAVs, or drones), to assist in the practices of foraging. Specifically, the project investigates the use of hobbyist drones for urban fruit spotting. The Drones for Foraging followed a participatory approach to RtD. Working together with Concrete Jungle we engaged in experience prototyping [10] and the staging participatory encounters [22] as an approach to RtD. The motivation was to undertake what Halse, et al. call "rehearsing the future" [33]: to use design as a means of exploring how contemporary practices might change, with the introduction of new technologies or services.

In precision agriculture, a range of technologies are used to monitor crops and conditions, thereby producing data to aide decision-making in farming. These technologies include geographic information systems (GIS), remote imaging, and environmental sensors. UAVs are often used as part of the data collection process as they provide a unique and useful vantage for collecting images. Inspired by such practices in precision agriculture, we worked together Concrete Jungle to explore how hobbyist drones might assist in the monitoring fruit trees. If such technologies were valuable to industrial agriculture, might they be valuable to foraging? And if so, how would the technologies and associated services need to be re-designed to support a decidedly different kind of agriculture practice?

\section{Common Interaction Design as Speculating}

As our interest was not in designing drones but rather exploring the use of drones, we used an off-the-shelf hobbyist drone for our research: the Parrot 2.0. This entrylevel drone is relatively inexpensive, can be flown out-of- 
the-box and comes equipped with two cameras. In addition, a GPS unit can be added to the device and there is a software developers kit (SDK) that enables customization of the flight application.

Our design work consisted of four activities. The first was test flights with the drones in Atlanta, to investigate their basic functionality and their capacity to capture images of fruit trees and bushes. The second was the development of custom software to aid in fruit spotting (See Image 4). In some cases, the custom software was developed using the Parrot's Software Development Kit (SDK), in other cases the software remained a paper prototype. The third was the use of imaging software (ImageJ, http://imagej.nih.gov/ij/) for the analysis of images captured by the drone. The last was the exploration of the role that the drone could play as part of a civic service, through diagrams and use cases. Each of these activities is common to interaction design. And yet, we argue, these activities also comprise research through design because it is through these activities that we come to understand the conditions and consequences of use.

\section{Conclusion}

The Drones for Foraging project builds upon trends in participatory design that engage communities in exploring civic futures $[13,14,26]$. These explorations are decidedly speculative in that there is not necessary any intention or desire that the designs be realized. Instead, these engagements should be understood as a mode of cooperative inquiry, a joint exploration of what-might be. Drones may be a viable solution for supporting the practices of foraging in some contexts, but they are not certainly not the best solution. They are fragile and finicky. The point of the project, however, is not effectiveness or efficiency, but rather, to explore through material and experiential means, alternative configurations of resources and practices.

With the Drones for Foraging project, our intent was to explore how technologies of precision agriculture, meant to increase yield and thereby profitability, might be appropriated for use with a decidedly non-precise agriculture, meant to distribute an abundance and excess to those in need. What we discovered through this process was that while that might be technologically possible, other issues thwart a simple transfer of technology and practice across scale. For instance, there are issues of policy. Drones, in fact, are regulated. Curiously, the use of drones for foraging elides current regulations applied to agricultural drones because the agriculture-the fruits collected-are not sold, but instead is given away. Thus, the drone use does not count as commercial. Instead, the limitation on the drone was the use of them for researchanother category with strict limitations. Encountering these policy categories and consequences was, at least as much if not more so than any technological issues, a primary finding of this speculative RtD project.

\section{DISCUSSION I (REFLECTIONS ON RTD)}

In what follows we examine each project to identify research-through-design tactics. We compare the projects across four dimensions in order to outline some specific tactics for RtD. The four dimensions were arrived at through a process of reflectively analyzing the projects in comparison to one another and identifying broad commonalities through affinity diagramming. First, we discuss dimension of time: when do the conditions under scrutiny seem to take place? Next, we discuss the dimension of representation, or how the designed objects reflect upon their subject matter. Third, we discuss the dimension of design discourse, or what the project reveals about the activities of design that they come from. Finally, we discuss the dimension of speculation: in what capacity do these projects speculate on current conditions? We believe these four dimensions-time, representation, discourse, and speculation-offer ways to compare and contrast these projects, as well as offer insights into other RtD projects.

\section{RtD as Representations of Systems Yet-to-Come}

The Division of Domestic Data illustrates an anticipatory approach to RtD. While design fundamentally deals with "that-which-does-not-yet-exist" [37] through the proposals, prototypes, and representations of products, services, and systems, the project is oriented toward a time horizon that is both contingent and indeterminate. The Division of Domestic Data traces a particular future scenario that both extrapolates on existing conditions-statutes related to divorce - and erases the intermediate time that leads to the discussed conditions. The project depends on a time horizon that is distinctly in the future without being locatable on a particular timeline.

The project represents these future conditions through a series of icons and supporting materials. Rather than specifying systems yet-to-come, the project populates the world of those systems. The icons are artifacts of the processes of post-digital divorce, and the pamphlet and sketches outline a system and process that recedes into the background. These representations point toward a new, speculative process, indirectly representing it through traces and residues of existing systems like it.

The Division of Domestic Data is, then, an example of design before design [23]. By design before design, we mean that the project speculates on future conditions by assuming the existence of other (here, extrapolated and contingent) conditions. As an anticipatory speculation, we mean that the project is forward looking, and responds to emerging conditions. Rather than assuming what is necessarily probable, the project anticipates alternatives that are possible in order to reflect on the steps that lead to such a scenario (i.e. design before design). Such an anticipatory speculation is the common mode of speculative design, performing a diegetic function, and pointing towards an imagined future [5]. 


\section{RtD as Prototyping Systems}

In many ways, Data Democracy could be considered as an archetypal research through design project: it is a prototype system that uses existing technologies to consider how new arrangements of these technologies might operate in the future. Here, the prototype's design is making a rhetorical claim towards potential futures as embodied in the system.

Data Democracy as a prototype is an example of speculative mismatch of technology and application. Here, software meant for market research or semantic analysis takes the role of governance, and the project materializes the implications. In this case, the research contribution comes from the prototyping process itself: taking seemingly-disparate ideas, putting them together, considering how a prototype might operate from a technical standpoint, and constructing it.

This is an example of design at design time. It responds to contemporary issues that hybridize data, governance, and civic infrastructure and-through prototyping-builds a new way to think through this intersection. It sets a frame and uses research through design practice to reflect on this domain hybridization. By employing functional aspects of a working system, rhetorical constructs emerge through both the construction and use of the prototype [6].

\section{RtD as Use of a System}

The Drones for Foraging project is an example of a research through design in which the research happens through the use of the system. As we have commented on elsewhere [17] while the idea of uses as design may seem unusual, with new platforms, experimentation through use is a common, and necessary, first step.

As previously mentioned, one way to understand the Drones for Foraging project is an appropriation of a technology. The activities and inventiveness of appropriation, then, become a mode of experimentation. Prototyping occurs not through the constructions of a device anew, but rather through an imaginative staging of use - the use of the device in a novel context, for novel purposes. Through this, the design researcher comes to understand the potentials and limitations of that use.

Drones for Foraging project, then, is an example of design research after design. The phrase design after design is often used in participatory design to call attention to users making modifications to products, well after the projects have been officially designed and are in circulation [23]. We argue a similar activity is possible with design research. We might also, then consider the Drones for Foraging project as a kind of ad-hoc speculation: a mode of speculation that is negotiated between the questions and conditions motivating the inquiry and capacities of the preexisting system.

\section{DISCUSSION II (REFLECTIONS ON CIVICS)}

The explicit impetus for this work was to use a research through design approach to explore possible alternative configurations and manifestations of civics. Put directly, how does our design explorations prompt new ways of conceptualizing what civics are or might be? The answers to this question are undeniably interpretative, based upon our reflection on our design process and artifacts. This builds upon trends in reflective HCI and related methodologies of knowledge generation through design and interpretation as post-hoc sense-making and theorizing [3]. In what follows we present and discuss these reflections and insights. It is important to note that the themes are not mutually exclusive-some projects may span themes. The themes are also not exhaustive; these are but three themes we developed from our reflective of our projects. Still, we believe these themes are useful. In addition to demonstrating a speculation on civics, these themes are also generative: capable of working as starting points for new research through design exploration of the space of civics.

\section{Mediated Civics}

The Division of Domestic Data project presents a notion of mediated civics. By mediated civics we mean activities, processes, and sites that come to be understood as civic only through their particular framing as civic. The central site of civic activity in the Division of Domestic Data is the file, broadly construed. Labeling, transferring, deleting, or locking files are not inherently civic activities. These activities occur for various personal, professional, and logistical reasons. For example, deleting a file from a computer might be an act to remove clutter from a personal computer, to protect corporate property, or simply to save limited space. Deleting a file becomes a civic concern only through the contracts that regulate the actions of individuals or parties in order to protect the rights of others. Hence, ordinary activities are mediated into civic activities.

In this project, the activity of deleting a file becomes civic through the ways that digital property mediates and represents connections between individuals during marriage. Those connections are regulated by local, state, and federal laws due to the signed and officiated contractual structure of marriage, including the shared rights of spouses as well as legal indemnification in other civic settings (e.g. courts). Mediated civics frame ordinary, mundane, and personal activities as civic through the particular bodies that deem these activities in need of public protection. This framing is not abstract, but material [36]-civic participation occurs through the ways files are labeled, stored, and transferred.

The Division of Domestic Data modulates two core dimensions of civics: (1) the relationship between the public and private life and (2) the role of the state in constructing (and decomposing) civic units. These two dimensions are interrelated. While deletion of files can occur in the private setting, in instances described by the project, this activity is no longer of individual concern. John Dewey describes public matters as those matters that extend beyond the immediate parties involved [15]. As 
such, individual actions require intervention when an individual can restrict or disenfranchise another. This transformation of once-private activities into public concerns is also of interest in democratic systems as it impacts the ability of individuals to participate in various civic contexts, from voting to paying taxes. So far these explanations account for the regulation of traditional property. The Division of Domestic Data, then, speculates on the post-digital landscape that includes impositions like the removal of wireless service or the withholding of digital records. Like valued physical property, these possessions and services impact the ability of an individual to carry on with their daily lives, whether that is in the capacity of maintaining health insurance or in establishing a separate residence. Like the protections of existing statutes, the Division of Domestic Data highlights the pervasiveness of digital technologies and the questions the adequacy of established notions of civic entitlements.

\section{Computed Civics}

Data Democracy presents a notion of computed civics. Here we take civics as being constructed from the results of computation-computation becomes the material from which civic participation emerges. For example, a 311 system takes citizen's questions and concerns, storing them as information that can be accessed in the future and subsequently evaluated. Similarly, transportation planners count current automobile throughput when considering future roadway construction proposals. Computed civics understand the role and nature of civic participation-as well as planning - as things that can be represented computationally through quantification, calculation, and proceduralization. Here, the capacities of computation are applied to all kinds of activities, procedurally transforming them into something that can be reasonably interpreted as "civic."

Contemporary rhetoric around smart cities falls inside of this construction of civics [30,47]. This is the promise of sensors and algorithms providing more perfect knowledge about what is happening in a city, and that information being used to improve city services. Computed civics, then, has established roots in large scale data collection like the census, yet applies contemporary means and thinking related to so-called big data. Under a conception of computed civics, publics are being related to and understood as being primarily informational. Issues are not addressed as assemblages of perspectives that comprise $a$ public, but are taken en masse as being the public. This public is constructed from traces, metadata, and becomes collections of these attributes. Civics becomes data, just as data becomes civics.

Data Democracy engages with this understanding of civics by questioning the role of the state in this rhetorical move. By framing civics as a material that can become computational, certain questions emerge: How might representing individuals' data sources as a coherent public operate? Who gets to query civic data and infer results from it? And finally, what kind of assumptions are being made about polity in the process?

\section{Proxied Civics}

The Drones for Foraging projects presents a notion of a proxied civics. By proxied civics we mean a notion of governmentality, provisioning, and public life that is enabled, in part, by extra-state services. One version of proxied civics is the common neoliberal formulation of outsourcing government functions. Another, and the one we call attention to here, is citizen-led initiatives. These initiatives include a broad range of organizations and activities, ranging from franchised organizations such as Code For America to grassroots collectives such as Occupy Sandy [1].

In proxied civics what we see is a relation of publics to publics. Such a relation means clusters of people and things organized around an issue (i.e. a public) interface with, often working together with, other clusters of people and things (i.e. another public). Between these publics is a common larger issue, but the orientation toward that issue, and the ways of acting toward that issue are different. Systems and devices play a role with regards to action as they facilitate or thwart different modes of action by and between the publics. Material participation occurs through imaginative use - through the invention of new forms of action enabled by the possibility of a given technology or technological practice.

The Drones for Foraging project encapsulates this notion of a proxied civics in that it engages in the creative appropriation and adaptation of a technology toward an extra-state service provisioning. In particular, the project explores the use of drones to support and amplify the activities of an existing organization (Concrete Jungle) and its capacities to work with other organizations (by providing free produce) towards the broader objective of local food security. This is not to say that the technology itself is not the proxy to civics (that the drone is delegated a civic task) but rather that the use of the drone - as imagined through the research process - would enable and further the work of the organization to function as a proxy to typically state-managed services.

\section{CONCLUSION}

In this paper, we presented a series of RtD projects that we characterized as speculative civics. None of the design work was ever intended to be realized beyond the various prototype forms it took through the research. Rather, each project used activities and artifacts of design to explore future civic conditions and consequences. A common theme throughout the projects is the role of computation (in various modes) in our future civics. This work presents another perspective, then, on a range of contemporary themes, including those of digital citizenship and smart cities. 
In the process of these RtD projects, we identified tactics for RtD as well as themes in civics. The tactics of RtD were: Representations of Systems Yet-to-Come, Prototyping Systems, and Use as of a System. Each of these is a particular maneuver that can be used in used to explore, through design, the potential qualities of a speculative context. Each provides a way to gesture towards or outline a future just enough to reflect on it. The themes of civics that articulated were: Mediated Civics, Computational Civics, and Proxied Civics. These themes are not merely reflective analyses, these themes can also be generativestarting points for further RtD projects exploring the space of civics as it overlaps with trends in politics, governance, and technology.

As we continue the practice of speculation, particularly as a mode of RtD, it is important to acknowledge our own limitation and push for pluralism. Of course, notions of civics are diverse and dynamic. Our approach and our projects are grounded in our lived experience of $21^{\text {st }}$ century western democracy. Other approaches to civics exist that are significantly different, and from which one would likely draw significantly different implications for design.

\section{ACKNOWLEDGMENTS}

The authors would like to acknowledge Kirsten Boehner, Firaz Peer, Amanda Meng, and Andrew Nelson for their feedback.

Support for this work came in part from the Intel Science and Technology Center for Social Computing, as well as NSF Grant IIS-1523526.

\section{REFERENCES}

1. Eric Ambinder and David M. Jennings. 2013. The Resilient Social Network: Occupy Sandy and Supestorm Sandy.

2. Jeffrey Bardzell and Shaowen Bardzell. 2013. What is "Critical" About Critical Design? Proceedings of the SIGCHI Conference on Human Factors in Computing Systems, ACM, 3297-3306. http://doi.org/10.1145/2470654.2466451

3. Jeffrey Bardzell, Shaowen Bardzell, and Lone Koefoed Hansen. 2015. Immodest Proposals: Research Through Design and Knowledge. Proceedings of the 33rd Annual ACM Conference on Human Factors in Computing Systems, ACM, 2093-2102. http://doi.org/10.1145/2702123.2702400

4. David M. Berry. Critical Theory and the Digital. Bloomsbury Publishing. Retrieved September 24, 2015 from http://www.bloomsbury.com/us/critical-theoryand-the-digital-9781441166395

5. Julian Bleeker. 2009. Design Fiction: A Short Essay on Design, Science, Fact and Fiction. Retrieved February 15, 2013 from http://nearfuturelaboratory.com/2009/03/17/design- fiction-a-short-essay-on-design-science-fact-andfiction/

6. Ian Bogost. 2012. Alien Phenomenology or, What it's Like to Be a Thing. University of Minnesota Press, Minneapolis.

7. John Bowers. 2012. The Logic of Annotated Portfolios: Communicating the Value of "Research Through Design." Proceedings of the Designing Interactive Systems Conference, ACM, 68-77. http://doi.org/10.1145/2317956.2317968

8. Jed R. Brubaker. 2014. The Afterlife of Digital Identity. CHI'14 Extended Abstracts on Human Factors in Computing Systems, ACM, 343-346. http://doi.org/10.1145/2559206.2559964

9. Jed R. Brubaker, Lynn S. Dombrowski, Anita M. Gilbert, Nafiri Kusumakaulika, and Gillian R. Hayes. 2014. Stewarding a Legacy: Responsibilities and Relationships in the Management of Post-mortem Data. Proceedings of the SIGCHI Conference on Human Factors in Computing Systems, ACM, 41574166. http://doi.org/10.1145/2556288.2557059

10. Marion Buchenau and Jane Fulton Suri. 2000. Experience Prototyping. Proceedings of the $3 \mathrm{rd}$ Conference on Designing Interactive Systems: Processes, Practices, Methods, and Techniques, ACM, 424-433. http://doi.org/10.1145/347642.347802

11. Peter Cook (ed.). 1999. Archigram. Princeton Architectural Press, New York.

12. Mike Crang and Stephen Graham. 2007. SENTIENT CITIES Ambient intelligence and the politics of urban space. Information, Communication \& Society 10, 6: 789-817. http://doi.org/10.1080/13691180701750991

13. Christopher A Le Dantec, Mariam Asad, Aditi Misra, and Kari E Watkins. 2015. Planning with Crowdsourced Data: Rhetoric and Representation in Transportation Planning. CSCW'15: Proceedings of the 18th ACM Conference on Computer Supported Cooperative Work \& Social Computing, ACM Request Permissions, 1717-1727.

14. Christopher A. Le Dantec and Sarah Fox. 2015. Strangers at the Gate: Gaining Access, Building Rapport, and Co-Constructing Community-Based Research. Proceedings of the 18th ACM Conference on Computer Supported Cooperative Work \& Social Computing, ACM, 1348-1358. http://doi.org/10.1145/2675133.2675147

15. John Dewey. 2012. The Public and its Problems: An essay in political inquiry. Penn States Press, Philadelphia.

16. Carl Francis DiSalvo. 2009. Design and the Construction of Publics. Design Issues 25, 1: 48-63. 
17. Carl DiSalvo and Tom Jenkins. 2015. Drones for Foraging. 2nd Conference on Research Though Design.

18. Carl DiSalvo, Jonathan Lukens, Thomas Lodato, Tom Jenkins, and Tanyoung Kim. 2014. Making Public Things: How HCI Design Can Express Matters of Concern. Proceedings of the SIGCHI Conference on Human Factors in Computing Systems, ACM. http://doi.org/10.1145/2556288.2557359.

19. Anthony Dunne. 2006. Hertzian Tales: Electronic Products, Aesthetic Experience, and Critical Design. The MIT Press.

20. Anthony Dunne and Fiona Raby. 2014. Speculative Everything: Design, Fiction, and Social Dreaming. MIT Press, Cambridge, Massachusetts ; London.

21. Keller Easterling. 2014. Extrastatecraft: The Power of Infrastructure Space. Verso Books.

22. Pelle Ehn. 1988. Playing the Language-games of Design and Use-on Skill and Participation. Proceedings of the ACM SIGOIS and IEEECS TC-OA 1988 Conference on Office Information Systems, ACM, 142-157. http://doi.org/10.1145/45410.45426

23. Pelle Ehn. 2008. Participation in design things. Proceedings of the Tenth Anniversary Conference on Participatory Design 2008, Indiana University, 92101. Retrieved February 12, 2013 from http://dl.acm.org/citation.cfm?id=1795234.1795248

24. Daniel Fallman. 2003. Design-oriented humancomputer interaction. Proceedings of the SIGCHI Conference on Human Factors in Computing Systems, ACM, 225-232. http://doi.org/10.1145/642611.642652

25. Gabriele Ferri, Jeffrey Bardzell, Shaowen Bardzell, and Stephanie Louraine. 2014. Analyzing Critical Designs: Categories, Distinctions, and Canons of Exemplars. Proceedings of the 2014 Conference on Designing Interactive Systems, ACM, 355-364. http://doi.org/10.1145/2598510.2598588

26. Sarah Fox and Christopher Le Dantec. 2014. Community Historians: Scaffolding Community Engagement Through Culture and Heritage. Proceedings of the 2014 Conference on Designing Interactive Systems, ACM, 785-794. http://doi.org/10.1145/2598510.2598563

27. William Gaver. 2011. Making Spaces: How Design Workbooks Work. Proceedings of the SIGCHI Conference on Human Factors in Computing Systems, ACM, 1551-1560.

http://doi.org/10.1145/1978942.1979169

28. William Gaver. 2012. What should we expect from research through design? Proceedings of the 2012 ACM annual conference on Human Factors in Computing Systems, ACM, 937-946. http://doi.org/10.1145/2208516.2208538
29. William W. Gaver, Jacob Beaver, and Steve Benford. 2003. Ambiguity as a resource for design. Proceedings of the SIGCHI conference on Human factors in computing systems, ACM, 233-240. http://doi.org/10.1145/642611.642653

30. Adam Greenfield. 2006. Everyware: The Dawning Age of Ubiquitous Computing. New Riders Publishing, Berkeley, CA.

31. Oliver L. Haimson, Jed R. Brubaker, Lynn Dombrowski, and Gillian R. Hayes. 2015. Disclosure, Stress, and Support During Gender Transition on Facebook. Proceedings of the 18th ACM Conference on Computer Supported Cooperative Work \& Social Computing, ACM, 1176-1190. http://doi.org/10.1145/2675133.2675152

32. Maarten Hajer. 2003. Policy without polity? Policy analysis and the institutional void. Policy Sciences 36, 2: 175-195. http://doi.org/10.1023/A:1024834510939

33. Joachim Halse, Eva Brandt, Brendon Clark, and Binder (eds.). 2010. Rehearsing the Future. Danish Design School Press, Copenhagen.

34. Conor Linehan, Ben J. Kirman, Stuart Reeves, et al. 2014. Alternate Endings: Using Fiction to Explore Design Futures. CHI'14 Extended Abstracts on Human Factors in Computing Systems, ACM, 45-48. http://doi.org/10.1145/2559206.2560472

35. Jonathan Lukens. 2013. DIY Infrastructure and the Scope of Design Practice. Design Issues 29, 3: 14-27. http://doi.org/10.1162/DESI_a_00218

36. Noortje Marres. 2012. Material Participation: Technology, the Environment and Everyday Publics. Palgrave Macmillan, Basingstoke.

37. Harold G Nelson and Erik Stolterman. 2012. The Design Way: Intentional Change in an Unpredictable World. The MIT Press, Cambridge, Massachusetts.

38. William Odom. 2015. Understanding Long-Term Interactions with a Slow Technology: An Investigation of Experiences with FutureMe. Proceedings of the 33rd Annual ACM Conference on Human Factors in Computing Systems, ACM, 575-584. http://doi.org/10.1145/2702123.2702221

39. William Odom, Abi Sellen, Richard Harper, and Eno Thereska. 2012. Lost in Translation: Understanding the Possession of Digital Things in the Cloud. Proceedings of the SIGCHI Conference on Human Factors in Computing Systems, ACM, 781-790. http://doi.org/10.1145/2207676.2207789

40. William Odom, John Zimmerman, and Jodi Forlizzi. 2010. Designing for Dynamic Family Structures: Divorced Families and Interactive Systems. Proceedings of the 8th ACM Conference on Designing Interactive Systems, ACM, 151-160. http://doi.org/10.1145/1858171.1858199 
41. William Odom, John Zimmerman, and Jodi Forlizzi. 2014. Placelessness, Spacelessness, and Formlessness: Experiential Qualities of Virtual Possessions. Proceedings of the 2014 Conference on Designing Interactive Systems, ACM, 985-994. http://doi.org/10.1145/2598510.2598577

42. James Pierce, Phoebe Sengers, Tad Hirsch, Tom Jenkins, William Gaver, and Carl DiSalvo. 2015. Expanding and Refining Design and Criticality in HCI. Proceedings of the 33rd Annual ACM Conference on Human Factors in Computing Systems, ACM, 20832092. http://doi.org/10.1145/2702123.2702438

43. Steven Poole. 2014. The truth about smart cities: "In the end, they will destroy democracy." The Guardian. Retrieved September 15, 2015 from http://www.theguardian.com/cities/2014/dec/17/truthsmart-city-destroy-democracy-urban-thinkersbuzzphrase
44. M. T. Stauffer. 2002. Utopian Reflections, Reflected Utopias: Urban Designs by Archizoom and Superstudio. AA Files: 23-36.

45. Joshua Tanenbaum. 2014. Design Fictional Interactions: Why HCI Should Care About Stories. interactions 21, 5: 22-23. http://doi.org/10.1145/2648414

46. Cameron Tonkinwise. 2015. Just Design. Medium. Retrieved September 24, 2015 from https://medium.com/@camerontw/just-designb1f97cb3996f

47. 2012. How to Transform a City: Lessons from the IBM Smarter Cities Challenge. Retrieved from http://asmarterplanet.com/files/2012/08/SmarterCities-WhitePaper_031412b1.pdf

48. Open City - Civic apps built with open data. Retrieved from http://opencityapps.org 